\title{
Gráficos comparativos entre países de las personas contagiadas por COVID-19
}

\section{Comparative charts among countries of people infected with COVID-19}

Artículo de Investigación Científica. Fecha de Recepción: 30/05/2020. Fecha de Aceptación: 14/06/2020

DOI: http://doi.org/10.17981/bilo.2.1.2020.7

\author{
Luz Verbel-Buelvas \\ Universidad de la Costa CUC. Barranquilla, (Colombia) \\ lverbel@cuc.edu.co \\ Jeizon Mejía-Villareal \\ Universidad de la Costa CUC. Barranquilla, (Colombia) \\ Jmejía64@cuc.edu.co \\ Hernando Manjarres-Gomez \\ Hmanjarr2@cuc.edu.co \\ Universidad de la Costa CUC. Barranquilla, (Colombia) \\ Alexander Troncoso-Palacio \\ Universidad de la costa CUC, Barranquilla, (Colombia) \\ atroncos1@cuc.edu.co
}

Para citar este artículo:

L. Verbel-Buelvas, J. Mejía-Villareal, H. Manjarres-Gomez, A. Troncoso-Palacio, "Gráficos comparativos entre países de las personas contagiadas por covid-19”, BILO, vol. 2, no. 1, 2020. DOI: http://doi.org/10.17981/bilo.2.1.2020.7

\begin{abstract}
Resumen
Debido a la afectación sufrida en el mundo a causa de la pandemia por el covid-19, se surge la idea de hacer un comparativo entre los países con mayor número de contagios para lo cual se utilizan algunas de las herramientas de control calidad. Se inicia descargando información de nueve sitios web, donde se encontró la información necesaria para la aplicación de dichas herramientas, las cuales, facilitaron la identificación del número de contagios en 17 países en el primer cuatrimestre del año 2020, y las posibles causas que generaron la propagación del virus en la población, así mismo, identificar el mayor número de contagios en las ciudades de los países de Colombia y Ecuador. De igual forma, se identificó los países más afectados. Finalmente, se obtuvo que los diagramas utilizados fueron asertivos, ya que cumplieron con la función de corroborar la información recopilada a través de la investigación que se realizó, lo cual se reflejó en las gráficas realizadas, facilitando de esta manera el reconocimiento de los contagios para poder posteriormente ejecutar otros métodos de prevención.
\end{abstract}

Palabras clave: Control de calidad, herramientas de control de calidad, diagrama de Pareto e Ishikawa, Covid-19. 
BILO Vol. 2 no. 1, Enero- Junio de 2020

\begin{abstract}
Due to affectation suffered around the world caused by the pandemic caused by covid-19, arises idea to make a comparison between the countries with the highest number of infections, which, some of the quality control tools are used. Begins by download information from nine websites, where it was found the necessary information for application of these tools, which facilitated identification number of infected in 17 countries in the first four months of 2020, and the possible causes that generated the spread of the virus, likewise, it was identify the highest number of people infections in the cities of the countries of Colombia and Ecuador. Similarly, the most affected countries were identified. Finally, it was obtained that the diagrams used were assertive, since it was fulfilled the function of corroborating the information collected through the research that was carried out, which was reflected in the graphs made, thus facilitating the recognition of infections in order to subsequently execute other prevention methods.
\end{abstract}

Key Words: Quality control tools, Pareto and Ishikawa diagram, Covid-19

\title{
I. INTRODUCCIÓN
}

Según la información en [1], el Covid-19 es un virus que surge periódicamente en diferentes partes del mundo el cual puede generar muchos síntomas tales como infección respiratoria, gripa, que puede llegar a ser leve, moderada o grave. También, puede producir fiebre y cansancio. Para analizar lo que implica el virus Covid-19, se recopiló la información de 9 documentos de sitio web. De acuerdo con [2] [3] [4] [5], el Covid-19 se puede propagar por diferentes factores y esto causa diversos síntomas, los cuales pueden atentar con la vida misma. Sin embargo, existen métodos que se pueden implementar para evitar posibles contagios como el aislamiento social, evitar tocarse el rostro, lavarse las manos, entre otros, según en [6] [7] [8], y de esta forma combatir esta enfermedad. Basándonos en los datos de [9] [10] se logró implementar las herramientas de control de calidad; acorde con [11], éstas son utilizadas para determinar, medir, analizar y posteriormente proponer soluciones a los problemas identificados que interfieren y perjudican con el rendimiento de los procesos causando un desequilibrio, ayudando de esta forma a mejorar los indicadores de calidad. Estas herramientas cumplen con la principal función de mejorar todo resultado final de cualquier actividad, superando así lo establecido. Tras este enfoque, se utilizó como principal apoyo el diagrama de Ishikawa, Histograma y diagrama de Pareto. Mediante el diagrama de Ishikawa, se pudo identificar los posibles problemas que ha ocasionado gran número de contagios del Covid-19 en la actualidad, ya que según [12], es una herramienta para el análisis de los problemas que básicamente representa la relación entre un efecto y todas las posibles causas que lo ocasionan. De igual manera, se obtuvo información sobre la ciudad más afectada en el país de Ecuador y Colombia mediante la herramienta de Histograma. Ésta conforme a lo dicho en [13], es una representación gráfica que brinda la posibilidad de establecer de manera visual, ordenada y fácilmente comprensible todos los datos numéricos que pueden ser difíciles de entender. También se identificó la frecuencia de muertes a nivel mundial a causa del Covid-19 a través del Diagrama de Pareto, reflejando así los "pocos vitales" y los "muchos triviales". Teniendo claro lo anteriormente expuesto, se logró conocer la actualidad mundial por el Covid-19, y de esta forma tener en cuenta medidas de protección.

\section{ESTUDIOS PRIMARIOS DE LA LITERATURA}

En el presente documento se habla sobre la principal problemática mundial que se está enfrentando en la actualidad como lo es el Covid-19; éste es una enfermedad infecciosa causada por el coronavirus el cual ha causado un fuerte impacto con gran número de contagios en distintas partes del mundo. Tras lo anteriormente expuesto, se realizó una serie de investigación sobre los contagios debido a este factor en 17 países durante el primer cuatrimestre del 2020. Se recopiló la información de 9 documentos de sitio web que suministraron datos significativos. Acorde a [2] [3] [4] [5], el Covid-19 se puede adquirir por distintos medios, los cuales ocasionan síntomas leves, moderados o graves que pueden ocasionar posteriormente la muerte. Para evitar posible positivo del virus es importante tener en cuenta ciertos mecanismos de protección según lo establecido en [6] [7] [8], como lo es el lavarse las manos constantemente, evitar reuniones públicas y contacto cercano, usar tapabocas, entre otras, para poder combatir dicha enfermedad. Basándonos en los datos de [9] [10], se logró implementar el diagrama de Ishikawa, Histograma y diagrama de Pareto. El diagrama de Ishikawa según [12], es una herramienta que consiste en una representación gráfica que permite visualizar las causas que ocasiona un determinado problema, ésta es ampliamente utilizada dado que orienta la toma de decisiones al abordar las bases que determinan un desempeño deficiente. debido a esto se realizó un diagrama de Ishikawa que nos permitió identificar las causas que ocasionan el contagio del Covid-19 y los efectos que éste produce. Frente a los resultados obtenidos, se puede confirmar que el diagrama Ishikawa es una herramienta sumamente importante ante el análisis de un determinado problema gracias a su nivel de desarrollo y su facilidad interpretativa. Por otra parte, se utilizó de igual manera la herramienta de Histograma, el cual acorde con [13], cumple con la función de exponer gráficamente números, variables y cifras de modo que los resultados se visualicen más clara y ordenadamente. Sabiendo esto, se pudo reconocer fácilmente el nivel de propagación que se está enfrentando en las ciudades con mayor número de contagios en el país de Ecuador y 
Colombia (tomados como ejemplo para esta representación gráfica). También, se utilizó el diagrama de Pareto el cual conforme a lo dicho en [14], consiste en un gráfico de barras que clasifica de izquierda a derecha en orden descendente las causas o factores detectados en torno a un fenómeno, a través de ésta herramienta se pudo identificar los factores "pocos vitales" y "muchos triviales" con un $80 \%$ y $20 \%$ en medio del Covid-19, teniendo en cuenta los contagios actuales. De esta forma, se obtuvo una información satisfactoria ante la presente amenaza y así tener en cuenta ciertos mecanismos que ayuden a la prevención del coronavirus. De igual forma iniciar con medidas de corrección que garanticen un mejor sistema de protección en la población ciudadana como se sugiere en [7]. El objetivo principal de la presente investigación es conocer la actualidad mundial frente al Covid-19 a través del diagrama de Ishikawa, Histograma y diagrama de Pareto, para poder identificar la raíz que ocasiona la propagación ligera y así, posteriormente hallar una posible solución a estos mismos.

\section{METODOLOGÍA}

En la presente investigación se permite conocer el nivel de contagios debido a la pandemia del Covid-19 que se está enfrentando actualmente a nivel mundial a través de la recopilación de información de 9 artículos relacionados con este virus. Los cuales proporcionaron datos significativos para la utilización del diagrama de Ishikawa, Histograma y Pareto; estos permitieron identificar los factores que originan la propagación ligera del Covid-19, cumpliendo así, con resultados asertivos que posibilitaron la iniciativa de tomar métodos preventivos para evitar mayor número de contagios. Lo anterior se refleja en el siguiente diagrama:

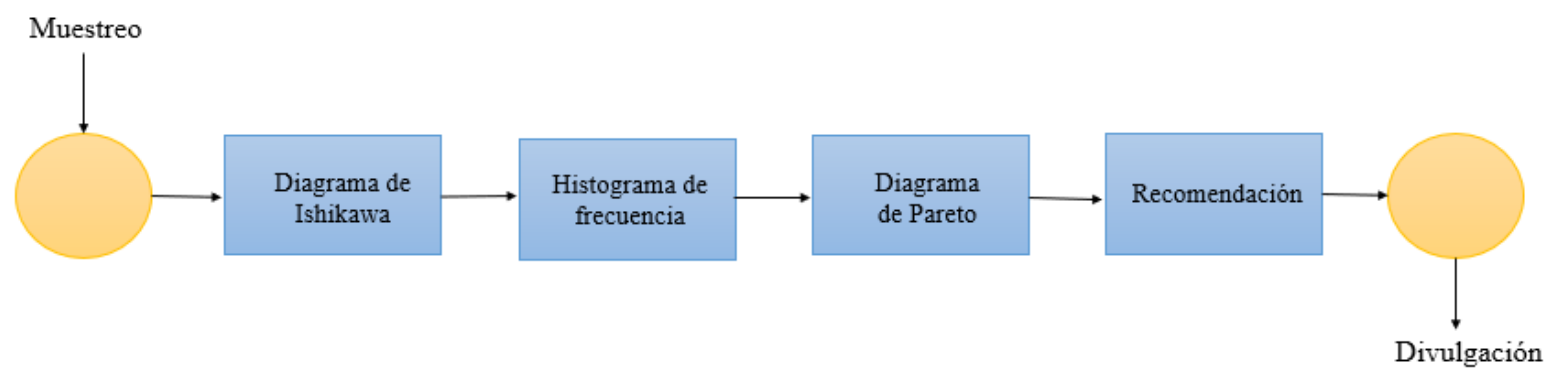

Figura 1: Flujograma de la metodología

\section{DESARROLLO}

En esta sección, se pretende dar a conocer los resultados obtenidos mediante la recopilación de datos establecidos a nivel mundial tras la pandemia del Covid-19. Las herramientas que se utilizaron para llevar a cabo la investigación fueron: Diagrama de Ishikawa, Histograma y Diagrama de Pareto.

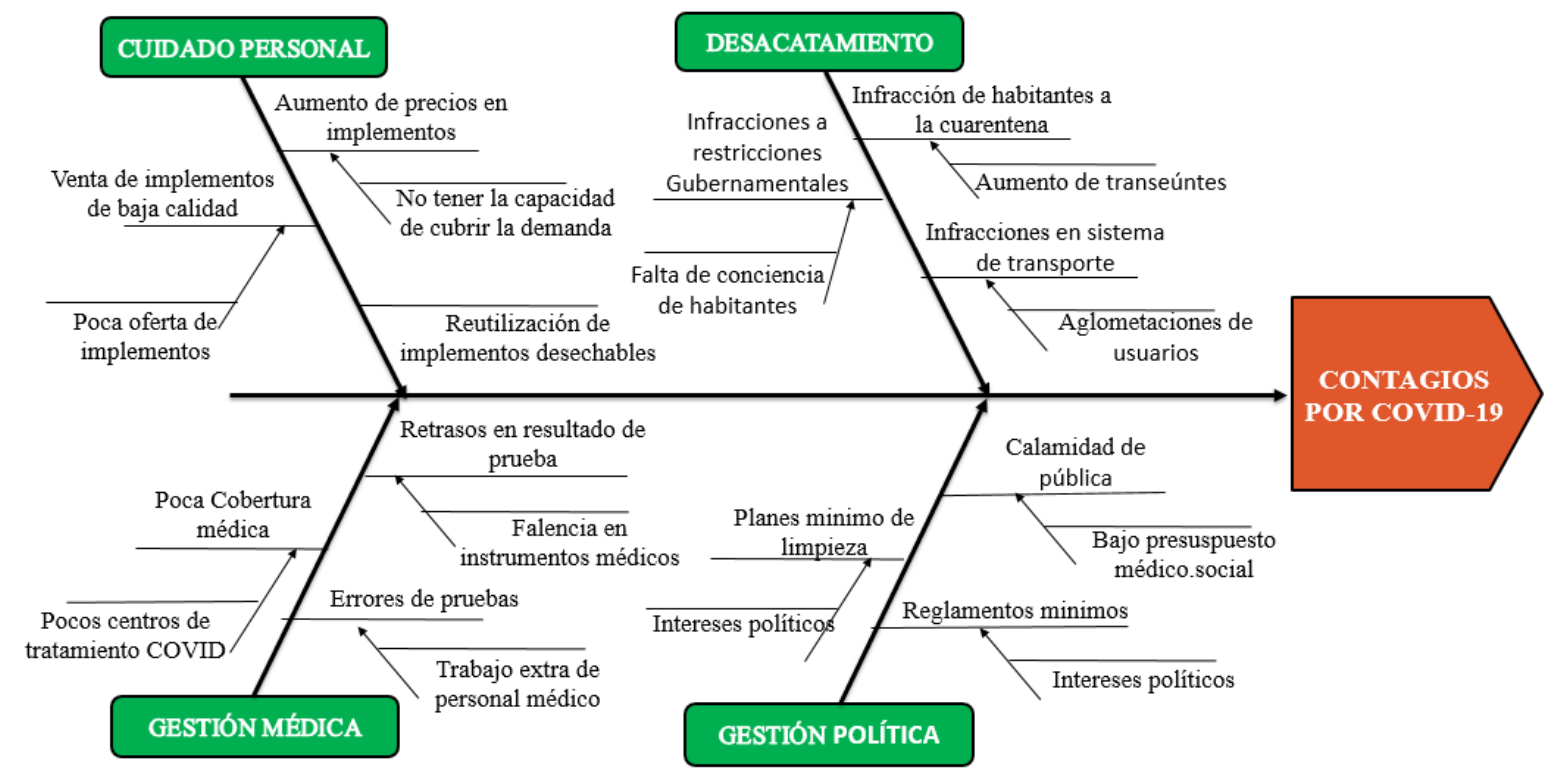


Figura 1: Diagrama de Ishikawa

En el diagrama anterior, se especifican las principales causas de contagios del Covid-19 en la sociedad, las causas más críticas se concentran en el desacatamiento a leyes y reglamentos gubernamentales por parte de la ciudadanía, como: transitar en lugares públicos sin ningún motivo alguno y aglomeraciones de personas que permiten que el virus pueda transmitirse por contacto, siendo esta la manera más rápida de contagios generando el aumento exponencial de los casos por este virus. Sin embargo, el tener un cuidado personal como uso de tapabocas, guantes y elementos de aseo personal también genera el aumento de contagio

Para la realización del Histograma se tomó como ejemplo el país de Ecuador y Colombia. Identificando así, las ciudades más afectadas frente al Covid-19 según en [9] [10].

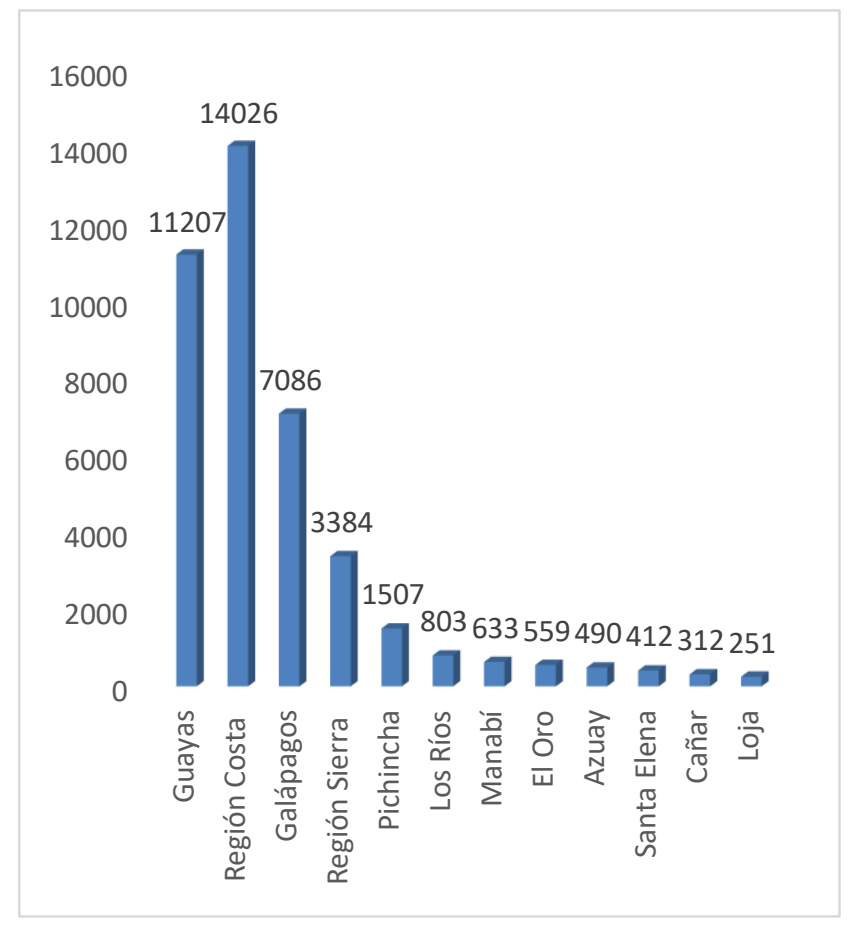

Gráfico 1: Datos de las 12 ciudades más afectadas frente al Covid-19 en el país de Ecuador.

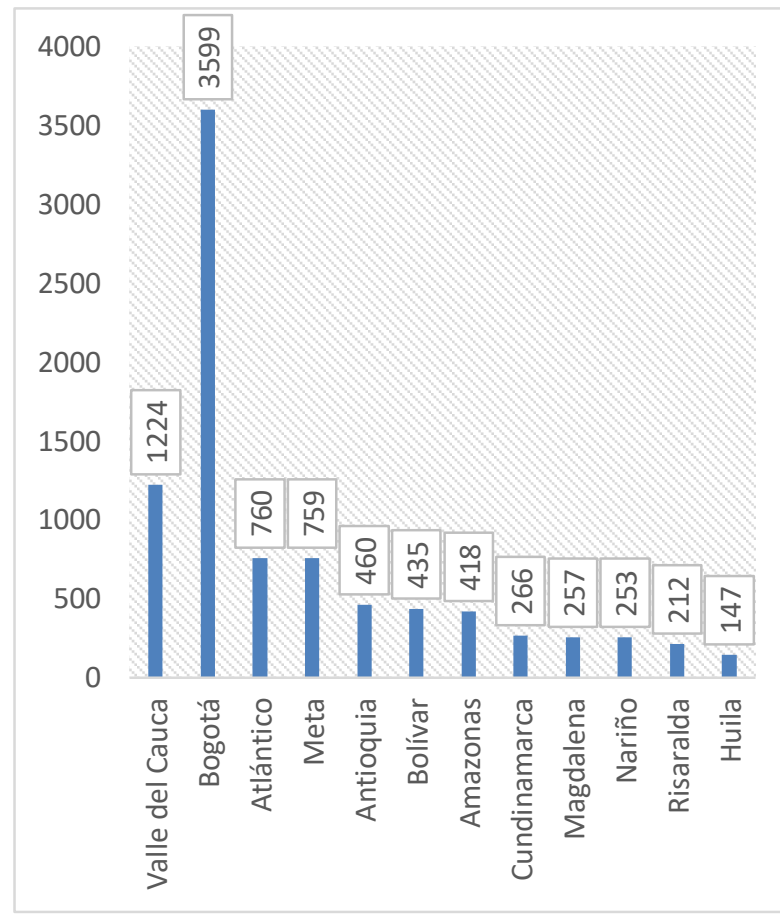

Gráfico 2: Datos de las 12 ciudades más afectadas frente al Covid-19 en el país de Colombia.

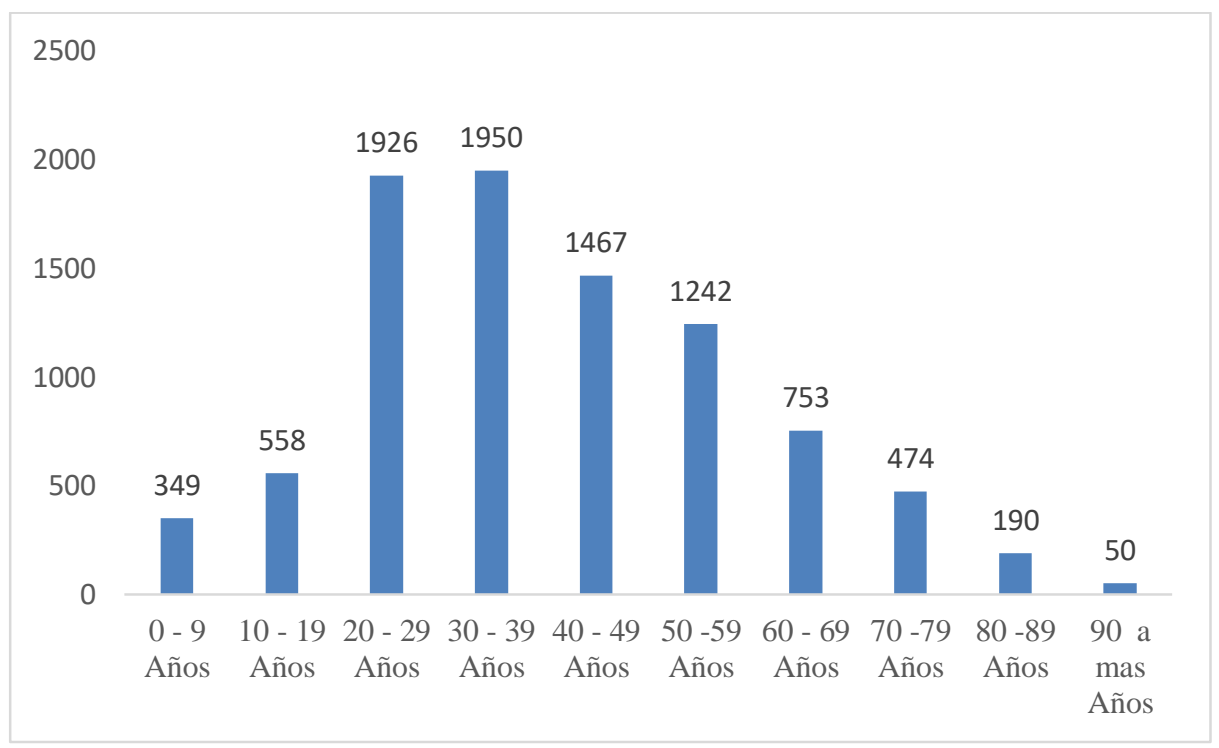

Gráfico 3: Datos de la cantidad de contagiados de acuerdo con las edades en el país de Colombia. 
BILO Vol. 2 no. 1, Enero- Junio de 2020

Para la realización del diagrama de Pareto, se recopiló la información actual de los 15 países más afectados frente al Covid-19 de acuerdo con [15].

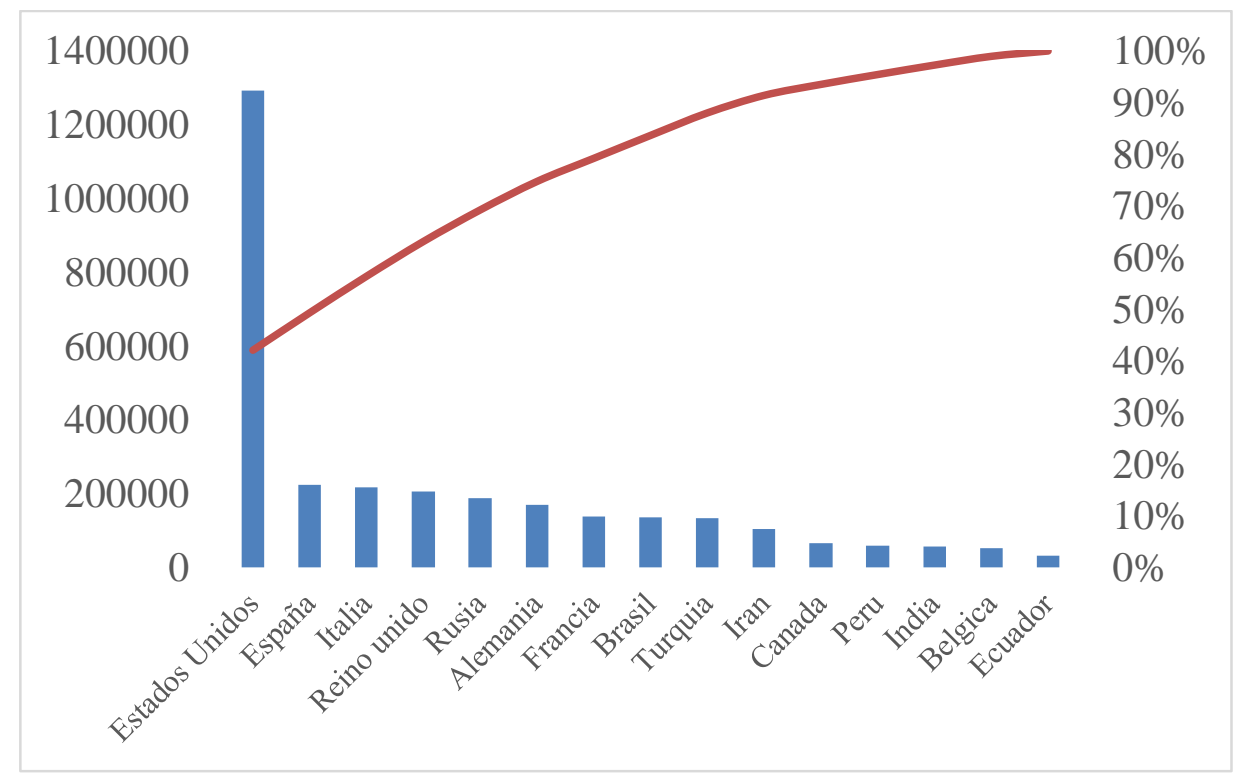

Gráfico 4: Datos de las personas contagiadas en 15 países.

De acuerdo con el anterior diagrama de Pareto se puede concluir que el mayor número de contagios del Covid-19 se encuentra entre los seis (6) primeros países, siendo estos los "pocos vitales" con un porcentaje del 80\%, por ende, se debería implementar medidas para la reducción de la propagación. Por otro lado, están los países con el menor número de contagios, siendo estos los "muchos triviales" con un porcentaje del $20 \%$.

\section{CONCLUSIÓN}

Finalmente, con los diagramas de Ishikawa, Histograma y de Pareto, ayudaron con el objetivo de la investigación, el cual consistía en identificar los países más afectados frente al Covid-19, siendo esto reflejado en las gráficas desarrolladas, y asimismo conocer las causas principales que aceleran la propagación de contagios, para así, tomar medidas de prevención y protección que ayuden a la reducción de esta pandemia.

\section{AGRADECIMIENTOS}

Agradecemos como primera instancia a Dios por permitirnos experimentar la realización de un artículo bajo la sabiduría que él nos ha otorgado, a la Universidad de la Costa por brindarnos todas las herramientas de investigación necesarias a lo largo de este proceso.

\section{REFERENCIAS}

[1] L. S. E. D. TODOS, «CORONAVIRUS (COVID-19),» 2404 2020. [En línea]. Available: https://www.minsalud.gov.co/salud/publica/PET/Paginas/Covid-19_copia.aspx.

[2] A. A. o. Pediatrics, «Healthy Children,» 15 05 2020. [En línea]. Available: https://www.healthychildren.org/spanish/health-issues/conditions/chest-lungs/paginas/2019-novelcoronavirus.aspx.

[3] CUIDEO, «CUIDEO,» 1103 2020. [En línea]. Available: https://cuideo.com/blog-cuideo/coronavirus-covid19-que-es-sintomas-y-medidas-de-prevencion/.

[4] M. CASTILlO, «Unir la Universidad en internet,» $27 \quad 02 \quad 2020$. [En línea]. Available: https://www.expansion.com/sociedad/2020/02/27/5e579e13e5fdea7c638b4619.html. 
[5] O. m. d. 1. salud, «Organizacion mundial de la salud,» [En línea]. Available: https://www.who.int/es/emergencies/diseases/novel-coronavirus-2019/advice-for-public/q-a-coronaviruses.

[6] M. Jonathan M. Miller, «Kids Health,» 04 2020. [En línea]. Available: https://kidshealth.org/es/parents/coronavirus-stop-spread-esp.html.

[7] C. p. e. C. y. 1. P. d. Enfermedades, «Centro para el Control y la Prevención de Enfermedades,» 2404 2020. [En línea]. Available: https://espanol.cdc.gov/coronavirus/2019-ncov/prevent-getting-sick/prevention.html.

[8] F. C.-1. Responde, «Florida Covid-19 Responde,» [En línea]. Available: https://floridahealthcovid19.gov/prevention/espanol/.

[9] LIBERO, «LIBERO,» 0805 2020. [En línea]. Available: https://libero.pe/ocio/1558396-coronavirus-ecuadorcovid-19-mapa-guayaquil-muertes-contagiados-guayas-quito-bono-emergencia-region-provincia-cantonultimas-noticias-viernes-8-mayo-20.

[10] TIKITAKAS, «TIKITAKAS,» 08 05 2020. [En línea]. Available: https://colombia.as.com/colombia/2020/05/07/tikitakas/1588851718_266422.html.

[11] I. T. EXCELLENCE, «BLOG CORPORATIVO,» $24 \quad 08$ 2017. [En línea]. Available: https://www.isotools.cl/herramientas-de-control-de-calidad/.

[12] G. TUTORIALES, «GESTION DE OPERACIONES,» $03 \quad 03$ 2017. [En línea]. Available: https://www.gestiondeoperaciones.net/gestion-de-calidad/que-es-el-diagrama-de-ishikawa-o-diagrama-decausa-efecto/.

[13] V. BEMBIBRE, «DEFINICION ABC,» 02 2009. [En línea]. Available: https://www.definicionabc.com/tecnologia/histograma.php.

[14] I. EMPRESA, «INGENIO EMPRESA,» 12 07 2016. [En línea]. Available: https://ingenioempresa.com/diagrama-de-pareto/.

[15] G. MAPS, «GOOGLE MAPS,» 0805 2020. [En línea]. Available: https://google.com/covid19-map/?hl=es-419. 